\title{
Evaluating Mental Health and Wellbeing of Postgraduate Researchers: Prevalence and Contributing Factors
}

\author{
Jelena Milicev ${ }^{1}$ (D) Mark McCann ${ }^{1}$ (D) Sharon A. Simpson ${ }^{1}$ (D) $\cdot$ Stephany M. Biello $^{2}$ (D) Maria Gardani $^{2}$ (D)
}

Accepted: 9 September 2021

(c) The Author(s) 2021

\begin{abstract}
High rates of mental ill-health in postgraduate researchers (PGRs) represent a significant barrier to life satisfaction and academic success. Nevertheless, there is little knowledge about the extent and origins of mental health problems of PGRs in the UK. The current study addresses this gap by investigating the prevalence and provenance of anxiety, depression, sleep problems, subjective mental wellbeing, and suicide behaviours of PGRs in the UK. An online survey $(\mathrm{N}=479)$ was used to measure the mental health outcomes and assess their relationships with demographic, trait and academic variables, policy, and social support. We found a high prevalence of mental ill-health and low levels of wellbeing in the current sample. Factors associated with poorer outcomes were female and non-binary gender, non-heterosexual identity, maladaptive perfectionism, workaholism and being in the $5^{\text {th }}$ year of study or above. Resilience, adaptive perfectionism, higher levels of social support and positive evaluations of progress and preparation, departmental climate, and supervisory relationship were associated with more positive outcomes. The current findings contribute new knowledge about the prevalence of mental health symptoms in PGRs in the UK, implying that institutional efforts to improve PGR wellbeing should include strategies to promote equality, diversity, resilience, integration, social support, and work-life balance of PGRs.
\end{abstract}

Keywords Anxiety $\cdot$ Depression $\cdot$ Diversity $\cdot$ Sleep $\cdot$ Suicide $\cdot$ Social support $\cdot$ Students

\section{Introduction}

Recent research into the mental health and wellbeing of postgraduate researchers (PGRs) ${ }^{1}$ has revealed high rates of psychological distress and mental ill-health. A study of 3659 PGRs in Flanders, Belgium suggests that one in two experience psychological distress, while one in three have or may be at risk of a common psychiatric disorder, such as anxiety and/or depression (Levecque et al., 2017). Reports from the US reveal even higher rates, with three in four doctoral students experiencing elevated academic stress, one in two reporting depression, and one in ten considering suicide (E. Smith \& Brooks, 2015; UC Berkeley Graduate Assembly, 2014; University of California Student Mental

Maria Gardani

maria.gardani@glasgow.ac.uk

1 MRC/CSO Social and Public Health Sciences Unit, University of Glasgow, Glasgow, UK

2 School of Psychology, Institute of Neuroscience and Psychology, University of Glasgow, 62 Hillhead Street, Glasgow G12 8QQ, UK
Health Committee, 2006). Similarly, an international study of postgraduates, mostly $\mathrm{PhD}$ students, from 26 countries $(\mathrm{N}=2279)$ indicated that around $40 \%$ experienced elevated symptoms of anxiety and/or depression (Evans et al., 2018), while a recent meta-analysis $(\mathrm{N}=1261)$ found that PGRs reported significantly higher levels of stress than the general population (Hazell et al., 2020).

Poor sleep is a common mental health complaint among postgraduate students and symptoms of insomnia often accompany those of depression and anxiety in this population (Levecque et al., 2017; Sheaves et al., 2016; UC Berkeley Graduate Assembly, 2014). While hyperarousal associated with feelings of stress and worry is considered to be the main contributor to insomnia (Kalmbach et al., 2018), poor sleep can be propelling and perpetuating anxiety in those at high risk (Goldstein et al., 2013) A recent meta-analysis estimated the prevalence of insomnia among university students at $18.5 \%$ (Jiang et al., 2015), compared to $7.4 \%$ of the general population of a similar age (Ohayon, 2002). There is strong evidence that students who experience insomnia

\footnotetext{
1 The current study uses the term postgraduate researcher to refer to postgraduate researchers at both master's and doctoral level.
} 
and nightmares are at a higher risk of suicidal thoughts and behaviours, compared to those without sleep problems (Russell et al., 2019). According to a recent meta-analysis $(\mathrm{N}=634,662), 1$ in 10 students have considered suicide in the past 12 months and 1 in a 100 have attempted it in this period, while around 3\% have attempted it in their lifetime. (Mortier et al., 2018). While this is in line with the Berkeley data reported above, much higher percentages were recorded among university students ${ }^{2}$ in the UK $(\mathrm{N}=1273)$, including PGRs. Over a third (37.3\%) of participants in this study were found to be at risk of suicidal behaviours, while 1 in 10 reported a past attempt to take their own life. Although the majority of the sample (88\%) were undergraduate students, prevalence did not differ significantly between undergraduates and postgraduates (Akram et al., 2020).

Nevertheless, only around 3\% of PGRs in the UK disclosed a mental health diagnosis to their institution in 2018/19 (Higher Education Statistics Agency, 2020). This is comparable to the prevalence of mental health problems in the general population, with around $5.9 \%$ and $3.3 \%$ of adults in England reporting anxiety and depression, respectively, and 5.4\% having had suicidal thoughts in the past 12 months (McManus et al., 2016). Large discrepancies between the institutional figures and those obtained from smaller survey studies indicate that many more PGRs may be experiencing mental ill-health without a formal diagnosis or choosing non-disclosure.

A number of individual, interpersonal and environmental factors have been explored in the context of PGR mental health and wellbeing. Gender and sexuality seem to play a prominent role, as female, transgender, non-binary, homosexual, bisexual and queer PGRs tend to report poorer mental health than their male and/or heterosexual counterparts (Evans et al., 2018; Hazell et al., 2020; Levecque et al., 2017; UC Berkeley Graduate Assembly, 2014). Resilience, perfectionism and workaholism have repeatedly been associated with wellbeing in educational and occupational settings. University students perceive resilience as a complex ability to cope and bounce back from adversity, which is key to a successful university and workplace experience (Holdsworth et al., 2018). Psychological resilience in students was linked to flourishing (Aswini \& Amrita, 2017), and to lower rates of psychological and somatic distress and academic burn out (Beasly et al., 2003; Ríos-Risquez et al., 2016). In turn, workaholism in $\mathrm{PhD}$ students corresponds to lower levels of job satisfaction and higher levels of stress and sleep problems (Caesens et al., 2014). Maladaptive perfectionists, focused on the perceived discrepancy between their own standards and achievements, report poorer mental health and

\footnotetext{
2 The term university students is used to refer to samples comprised of both undergraduate and postgraduate students.
}

life satisfaction than adaptive perfectionists and non-perfectionists. Conversely, adaptive perfectionists, characterised by a high drive for excellence, report the best mental health and wellbeing of the three (Moate et al., 2019).

Variations in the academic experience play an important role. High levels of academic engagement, interest in an academic career, and a positive view of one's academic progress and preparation have a positive association with mental health and life satisfaction (Caesens et al., 2014; Levecque et al., 2017; UC Berkeley Graduate Assembly, 2014). Also, both PGRs who are behind their research schedule and those ahead of it tend to experience poorer mental health than those meeting the schedule (Barry et al., 2018), highlighting the importance of work-life balance in PGR wellbeing (cf. Levecque et al., 2017). Field of study plays a part too, as arts and humanities have been linked to poorer mental health and life satisfaction than other fields (Lipson et al., 2016; UC Berkeley Graduate Assembly, 2014). Business studies and social sciences, in turn, seem to be associated with higher life satisfaction and decreased rates of depression. However, at $28 \%$ for business and $34 \%$ for social sciences, overall depression rates were still high (UC Berkeley Graduate Assembly, 2014).

Finally, social support has a strong positive association with PGR wellbeing. Higher levels of social support at university and feelings of being valued and included in one's department correspond to higher life and job satisfaction andlower psychological distress (Caesens et al., 2014; Hazell et al., 2020; Levecque et al., 2017; UC Berkeley Graduate Assembly, 2014). Typically, research supervisors and peers are the main sources of support (Rose, 2005; Väisänen et al., 2017) and PGRs who are more satisfied with their supervisory relationship(s) are happier, less depressed and more satisfied with life than those with less positive perceptions (Cowling, 2017; Evans et al., 2018; UC Berkeley Graduate Assembly, 2014). In turn, PGRs who report lower levels of general and work-related social support, including that from peers and supervisors, also report more perceived stress, psychological distress, and sleep problems (Caesens et al., 2014; N. G. Nelson et al., 2001). They are also more likely to consider leaving or suspending their studies (Slight, 2017).

PGRs in the UK who report a mental health condition experience lower satisfaction with life, poorer work-life balance, lower levels of social support and are more inclined to abandon their studies (Slight, 2017). Nevertheless, the evidence base related to PGR mental health and wellbeing is still young and fragmented (cf. Schmidt \& Hansson, 2018; Sverdlik et al., 2018). Most prevalence studies have been conducted in the US, warranting more research in other parts of the world to draw comparisons and conclusions about the generalisability of findings. Sverdlik and colleagues (Sverdlik et al., 2018) note that the literature on influencing factors often focuses on a single factor that is considered 'crucial', 
such as supervision or motivation, resulting in a limited understanding of the relative importance of multiple factors at play. The current study aims to address this gap, exploring the prevalence of mental health issues in a UK sample and the role of multiple individual and environmental factors. Our approach is in line with the ecological perspective of health (Bronfenbrenner, 1977; McLeroy et al., 1988) which posits that individuals are embedded within their environments and their health outcomes are products of interactions between many factors at different levels of influence. The current study focuses on the following: individual factors (demographics, traits and academic progress) interpersonal (supervisory relationship, social support), institutional/ cultural (field of study, departmental climate) and policy (funding).

\section{Materials and Methods}

\section{Ethics}

The study obtained ethics approval from the University of Glasgow (application number 300180043). Participants received information about the purpose of the study and what their participation will involve and gave informed consent prior to taking part. At the end of the survey, relevant academic literature on PGR wellbeing was signposted, as well as the sources of free psychological help and support.

\section{Participants}

A total of 479 PGRs (Table 1) from 47 universities in the UK completed the survey. There were 415 PGRs from Scottish universities (86.6\%), 55 from universities in England (11.5\%), 6 from Welsh universities (1.3\%) and 2 from universities in Northern Ireland $(0.4 \%)$. One participant was studying at the Open University (0.2\%) at an unspecified location. Participant age ranged from 21 to 73, with mean age of 31.1 (Median $=28 ; \mathrm{SD}=9.1$ ) years.

\section{Procedure}

Data were collected between December 2018 and July 2019 via Jisc Online surveys platform (onlinesurveys.ac.uk). Participants were asked to take part in a short PGR wellbeing survey. Email invitations were sent to PGRs at one large research-focused university ( $16 \%$ response rate), while other participants were recruited via social media and personal contacts. It was estimated that the survey took about $30 \mathrm{~min}$ to complete.
Table 1 PGR Demographic and Academic Characteristics ( $\mathrm{N}=479)$ (N)

\begin{tabular}{lr}
\hline & $\%$ \\
\hline Demographic characteristics & \\
Gender & \\
Male & 28.60 \\
Female & 69.31 \\
Other & 1.46 \\
Prefer not to say & 0.63 \\
Sexual orientation & \\
Heterosexual & 77.04 \\
Homosexual & 5.22 \\
Bisexual & 11.69 \\
Other & 3.13 \\
Prefer not to say & 2.92 \\
Academic characteristics & \\
Field of study & \\
SE & 27.56 \\
MVLS & 26.72 \\
Arts & 17.75 \\
Social science & 21.29 \\
Other & 6.68 \\
Type of funding & \\
Fully-funded & \\
Self-funded & 27.14 \\
Partially funded & 27.97 \\
Year of study & 19.42 \\
1 & 21.29 \\
3 & \\
4 & \\
\hline & \\
\hline & \\
\hline
\end{tabular}

$\mathrm{SE}=$ Science and Engineering $; \mathrm{MVLS}=$ Medical, Veterinary and Life Sciences

\section{Measures}

\section{Individual factors}

\section{Demographics}

Participants were asked to provide information on their age, gender, sexual orientation (Table 1)

Traits

Resilience Brief Resilience Scale (BRS; Smith et al., 2008) is a six-item measure that assesses the ability to bounce back or recover from stress. Scores range from 1 to 5, with higher scores related to higher resilience. The scale had good internal consistency, $\alpha=89$. 
Workaholism Seven questions thought to be particularly relevant to the PGR population were derived from the 25-item Work Addiction Risk Test (WART; Flowers \& Robinson, 2002; Robinson, 1999) to tap into the five dimensions of the scale: Compulsive Tendencies, Control, Impaired Communication, Inability to Delegate, and Self-Worth (Appendix A). Scores range from 7 to 28 , with higher scores indicating more severe workaholism. The scale had questionable internal consistency, $\alpha=0.66$.

Perfectionism Perfectionism was assessed using the 8-item Short Almost Perfect Scale (SAPS; Rice et al., 2014), capturing two major dimensions of perfectionism: Standards/ Adaptive Perfectionism (high performance expectations) and Discrepancy/Maladaptive Perfectionism (self-critical performance evaluations). Within the range of $8-56$, higher scores correspond to more pronounced perfectionism. Internal consistency was excellent, $\alpha=0.90$ for Standards, and $\alpha=0.91$ for Discrepancy.

\section{Academic progress}

Year of study Participants were asked to specify which year of study they were currently in, regardless of the full-time/ part-time status.

Satisfaction with academic progress and preparation Five questions were adopted from the Berkley Graduate Student Happiness and Well-Being survey (UC Berkeley Graduate Assembly, 2014) to enquire about timely progression, sense of preparedness for the challenges involved, view of the future, engagement, and availability of material resources (Appendix B). Score range was 5-35, with higher scores indicating more positive evaluations. The scale had acceptable internal consistency, $\alpha=0.79$.

\section{Interpersonal factors}

\section{Supervisory relationship}

Supervisory relationship was defined as a complex construct, comprised of the perceived expertise, quality of guidance, feedback and mentorship, as well as rapport and interpersonal support. (e.g. Ali et al., 2016; McAlpine et al., 2012). Two items were adapted from the Berkeley survey (UC Berkeley Graduate Assembly, 2014) and eight novel items were added to gauge PGR evaluation of supervisory relationship (Appendix C). Score range was 10-70, with higher scores indicating more positive evaluations. Internal consistency was excellent, $\alpha=0.92$.

\section{Social support}

Three items from the 12-item Interpersonal Support Evaluation List (ISEL; Merz et al., 2014) were used to assess tangible support, appraisal support and belonging (Appendix D). Score range was $0-9$, with higher scores indicating higher perceived social support. The scale had poor internal consistency, $\alpha=0.57$.

\section{Institutional/cultural factors}

\section{Field of study}

This was captured through the question about college/school of registration, with 5 options: 'Social Sciences', 'Science and Engineering', 'Medical, Veterinary and Life Sciences', 'Arts', and 'Other'.

\section{Departmental climate}

One question was adapted from The Graduate Student Happiness and Well-Being Report (UC Berkeley Graduate Assembly, 2014) and three novel items were added to assess the perceptions of departmental climate in terms of inclusion, discrimination, bullying and mental health support (Appendix E). Score range was 4-28, while higher scores denoted more positive perceptions. Internal consistency was acceptable, $\alpha=0.79$.

\section{Policy}

\section{Funding}

Participants specified whether their funding was 'full', 'partial', or they were 'self-funded'.

\section{Mental health outcomes}

\section{Anxiety}

Severity of anxiety in the past two weeks was assessed using The Generalized Anxiety Disorder-7 (GAD-7; Spitzer et al., 2006). Total score range is from 0 to 21 , while scores of 5 , 10 , and 15 represent cut off points for mild, moderate, and severe anxiety, respectively. The scale had excellent internal consistency in the current sample, $\alpha=0.91$.

\section{Depression}

Severity of depression symptoms in the past two weeks was measured using the nine-item Patient Health Questionnaire 
(PHQ-9; Kroenke et al., 2001; Kroenke \& Spitzer, 2002). Scores range from 0 to 27 , while scores of $5,10,15$, and 20 are cut off points for mild, moderate, moderately severe and severe depression, respectively. The scale had excellent internal consistency, $\alpha=0.90$.

\section{Sleep/Insomnia symptoms}

Sleep Condition Indicator ( SCI; Espie et al., 2014) is an 8 -item scale that evaluates insomnia disorder considering both sleep quality and daytime functioning. Scores range from 0 to 32, with scores of 16 and below indicating poor sleep/insomnia. Internal consistency was good, $\alpha=0.88$.

\section{Mental wellbeing}

Short Warwick Edinburgh Mental Wellbeing Scale (SWEMWBS; Stewart-Brown et al., 2009) consists of seven positively phrased items that evaluate mental wellbeing on a 5 -point Likert-response format from 1 (none of the time) to 5 (all of the time). The scale contains 5 items that measure eudaimonic factors (psychological functioning and selfrealisation) and 2 that refer to hedonic factors, i.e. positive affect. Score range is 7-35, with higher scores corresponding to higher wellbeing. Low, medium and high categories of wellbeing were created based on scores that are at least one standard deviation below and above the mean, respectively (Ng Fat et al., 2017). Internal consistency in the current sample was good, $\alpha=0.86$.

\section{Suicidal behaviours and self-harming}

Suicide Behaviours Questionnaire - Revised (SBQ-R; Osman et al., 2001) is a brief four-item measure that taps into suicidal thoughts and past attempts. Scores range from 3 to 18 , where scores of 7 and above indicate an elevated risk of suicide. Internal consistency was good, $\alpha=0.84$. A single question from the PHQ-9 scale enquiring about thoughts of suicide and self-harming in the past two weeks was used to assess the prevalence of such thoughts in this period.

\section{Data analyses}

The current study is confirmatory in that all variables were selected on the basis of the extant literature, and exploratory in the sense that there was no previous knowledge of the relative importance of these variables when explored in conjunction. All analyses, including the scoring of mental health outcome scales, were conducted using $\mathrm{R}$ version 3.5.3. (R Core Team, 2019), according to the pre-registered analysis plan (Milicev et al., 2018). The purpose of the analyses was to describe the associations between the study variables rather than to determine causality or make predictions. To this end, Pearson's bivariate correlations and multiple linear regressions were performed. Sixteen participants (3.3\%) were excluded from the regression analyses due to missing values. All outcomes were non-negative continuous variables, with mostly skewed distributions and heteroskedastic model residuals. This was addressed by means of generalised linear models (GLMs), which are flexible generalisations of ordinary least squares regressions that are suitable for modelling non-negative skewed data, allowing for deviations from normality and homoskedasticity of error terms (Fahrmeir et al., 2013). The GLMs for anxiety, depression and sleep models were fitted using compound Poisson-gamma distributions from the Tweedie family. Tweedie distributions are a family of distributions comprising gamma, normal, Poisson and their combinations. These distributions have power variance functions of the form $\mathrm{V}(\mu)=\mu^{\mathrm{p}}$, where $p$ represents the Tweedie index parameter which specifies the particular distribution, e.g. normal $(p=0)$, Poisson $(p=1)$, gamma $(p=2)$ and inverse gaussian $(p=3)$. We have chosen compound Poisson-gamma distributions, as they are particularly useful for modelling continuous non-negative skewed data such as ours. In these distributions, power variance may take any value, as long as $1<\mathrm{p}<2$ (see Dunn \& Smyth, 2018). We calculated the exact power variance for our models using the $\mathrm{R}$ package "tweedie" (P. Dunn, 2021) and obtained the value of 1.2 for all three models. The wellbeing and suicide behaviours models comprised strictly positive values, and were fitted using lognormal and gamma log distributions, respectively, as QQ plots of quantile residuals and the Akaike Information Criterion (AIC: Burnham et al., 2011) indicated that these offer a better fit than Tweedie distributions. Generalised variance inflation factors (GVIFs) were obtained to assess multicollinearity (Montgomery et al., 2012). Model estimates represent $\log$ units, and statistical significance was defined as $p \leq 0.05$. The goodness of fit was assessed as the amount of deviance accounted for by the model (pseudo R-squared or D-squared value), which was calculated using the Dsquared function from the modEvA R package (Barbosa et al., 2021). A perfect model has no residual deviance, and its $D^{2}$ is 1 (Guisan \& Zimmermann, 2000). For an alternative analytical approach using hierarchical regression, see Appendix F.

\section{Results}

\section{Mental health and wellbeing}

\section{Anxiety and depression}

The percentage of PGRs who reported moderate or severe symptoms was $40.7 \%$ for anxiety and $40.5 \%$ for depression. 
Table 2 Descriptive Statistics of Predictor Variables and Bivariate Correlations between Study Variables

\begin{tabular}{lrrlllll}
\hline & $M$ & $S D$ & Anxiety & Depression & Sleep & $\begin{array}{l}\text { Wellbe- } \\
\text { ing }\end{array}$ & Suicidal behaviours \\
\hline Resilience & 3.1 & 0.8 & $-0.54 * * *$ & $-0.52 * * *$ & $0.58 * * *$ & $0.36 * * *$ & $-0.37 * * *$ \\
Workaholism & 20.2 & 3.5 & $0.42 * * *$ & $0.36 * * *$ & $-0.37 * * *$ & $-0.27 * * *$ & $0.3 * * *$ \\
Ad. Perf. & 23.9 & 4.3 & 0.08 & 0.02 & 0.04 & -0.03 & 0.07 \\
Malad. Perf & 18.9 & 6.4 & $0.45 * * *$ & $0.43 * * *$ & $-0.49 * * *$ & $-0.3 * * *$ & $0.36 * * *$ \\
Progress & 4.8 & 1.3 & $-0.46 * * *$ & $-0.54 * * *$ & $0.56 * * *$ & $0.38 * * *$ & $-0.27 * * *$ \\
Department & 4.8 & 1.4 & $-0.38 * * *$ & $-0.39 * * *$ & $0.37 * * *$ & $0.27 * * *$ & $-0.27 * * *$ \\
Supervisory & 5.3 & 1.3 & $-0.38 * * *$ & $-0.35 * * *$ & $0.32 * * *$ & $0.24 * * *$ & $-0.17 * * *$ \\
$\quad$ relationship & & & & & & & \\
Soc. support & 6.2 & 2.1 & $-0.26 * * *$ & $-0.29 * * *$ & $0.38 * * *$ & $0.22 * * *$ & $-0.27 * * *$ \\
\hline$*$ p $<.05 ; * p<0.01 * * * p<0.001$ & & & & \\
Ad. Perf. = Adaptive Perfectionism & & & & \\
Malad. Perf. = Maladaptive Perfectionism & & & &
\end{tabular}

Severe anxiety was reported by $20 \%$, while severe or moderately severe depression was reported by $22.3 \%$.

\section{Sleep/Insomnia symptoms}

In the past month, $46.3 \%$ of PGRs experienced symptoms of insomnia, while $37.4 \%$ reported having a problem with sleep for more than a year. Just under one third (29.2\%) felt their concentration and productivity were significantly affected by poor sleep.

\section{Wellbeing}

Low, medium and high categories of wellbeing were created based on the scores that are at least one standard deviation below and above the mean, respectively (see $\mathrm{Ng}$ Fat et al., 2017). In the current sample, mean wellbeing score was 22.1 $(\mathrm{SD}=5)$, with $68.9 \%$ experiencing medium levels of wellbeing, while $16.3 \%$ and $14.8 \%$ of the sample reported low and high levels of wellbeing, respectively. Measuring the eudaimonic dimension separately rendered the mean of $16.3 / 25(65.3 \%)$, while the mean score for the hedonic dimension was $5.8 / 10$ $(57.5 \%)$.

\section{Suicidal behaviours and self-harming}

Around a quarter of the sample (23.4\%) reported thoughts of suicide and/or self-harm in the past two weeks. More than a third (37\%) of PGRs had an increased risk of committing suicide compared to non-suicidal participants. Lifetime suicide ideation was present in $29.9 \%$, while $22.3 \%$ have had a plan to kill themselves and 5\% have already attempted suicide. In the past year, $14.5 \%$ have thought about suicide 'often' or 'very often', while $4.3 \%$ believed it is 'likely', 'rather likely' or 'very likely' that they would attempt suicide in the future.

Relationships between traits, academic progress, institutional relations, social support, and mental health

Descriptive statistics for independent variables and the bivariate correlations between traits, academic progress, supervisory relationship, social support, departmental climate, and mental health outcomes are shown in Table 2. Correlations between predictor variables are shown in Table 3 and those between outcome variables in Table 4 .

\section{Predictors of anxiety}

Age $(\beta=-.01, \mathrm{SE}=0.004, p=.002)$ and resilience were related to lower anxiety $(\beta=-.24, \mathrm{SE}=0.04, p<.001)$, and workaholism $(\beta=.04, \mathrm{SE}=0.01, p<.001)$ and maladaptive perfectionism $(\beta=.02, \mathrm{SE}=0.01, p<.001)$ to higher (Table 5). Positive evaluations of progress and preparation ( $\beta=-.08, \mathrm{SE}=0.03, p<.001)$ and supervisory relationship ( $\beta=-.06, \mathrm{SE}=0.02, p=.01$ ) were linked to lower anxiety, and so was studying medical, veterinary or life sciences $(\beta=-.15, \mathrm{SE}=0.08, p=.05)$. The model had no multicollinearity issues $(\mathrm{GVIFs}<2)^{3}$.

\section{Predictors of depression}

Older PGRs reported less depression $(\beta=-.01, \mathrm{SE}=0.004$, $p=.01$ ), while women reported significantly higher levels of symptoms than men $(\beta=.14, \mathrm{SE}=0.06, p=.03)$. Resilience was associated with lower levels of depression $(\beta=-.23$, $\mathrm{SE}=0.04, p<.001)$, while both workaholism $(\beta=.04$, $\mathrm{SE}=0.01, p<.001)$ and maladaptive perfectionism $(\beta=.02$, $\mathrm{SE}=0.01, p<.001)$ were related to more severe depression.

\footnotetext{
${ }^{3}$ This includes $\operatorname{GVIF}^{\wedge}(1 /(2 * \mathrm{Df}))$ values
} 
Table 3 Bivariate Correlations between Predictor Variables
Resilience Workaholism Ad. Perf Malad. Perf Progress $\begin{aligned} & \begin{array}{l}\text { Depart- } \\ \text { ment }\end{array} \\ & \begin{array}{l}\text { Supervisory } \\ \text { relationship }\end{array}\end{aligned}$

\begin{tabular}{|c|c|c|c|c|c|c|c|}
\hline Workaholism & $-0.26 * * *$ & & & & & & \\
\hline Ad. Perf & 0.00 & $0.32 * * *$ & & & & & \\
\hline Malad. Perf & $-0.40 * * *$ & $0.43 * * *$ & $0.30 * * *$ & & & & \\
\hline Progress & $0.41 * * *$ & $-0.10 *$ & $0.15^{* *}$ & $-0.28 * * *$ & & & \\
\hline Department & $0.26 * * *$ & $-0.14 * *$ & 0.09 & $-0.16^{* * *}$ & $0.45^{* * *}$ & & \\
\hline $\begin{array}{l}\text { Supervisory } \\
\text { relationship }\end{array}$ & $0.26^{* * *}$ & $-0.11^{*}$ & 0.03 & $-0.15 * * *$ & $0.46^{* * *}$ & $0.53 * * *$ & \\
\hline Soc. support & $0.22 * * *$ & $-0.20 * * *$ & 0.06 & $-0.26 * * *$ & $0.29 * * *$ & $0.26 * * *$ & $0.20 * * *$ \\
\hline
\end{tabular}

$* p<.05 ; * * p<.01 * * * p<.001$

Negative self-evaluation in terms of academic progress and preparation increased the likelihood of depression $(\beta=-.16$, $\mathrm{SE}=0.03, p<.001)$. The model had no multicollinearity issues with all GVIF coefficients $<2$.

\section{Predictors of sleep}

Bisexual orientation $(\beta=-.17, \mathrm{SE}=0.07, p=.01)$, and workaholism $(\beta=-.02, \mathrm{SE}=0.01, p=.01)$ were linked to poor sleep, while resilience contributed to good sleep $(\beta=.11$, $\mathrm{SE}=0.03, p<.001)$. Positive self-evaluation of progress and preparation was linked to better sleep $(\beta=.08, \mathrm{SE}=0.02$, $p<.001)$. No multicollinearity issues were detected $(\mathrm{GVIFs}<2)$.

\section{Predictors of wellbeing}

Non-binary gender $(\beta=-.16, \mathrm{SE}=0.08, p=.03)$, and homosexual orientation $(\beta=-.09, \mathrm{SE}=0.03, p=.01)$, were associated with lower levels of wellbeing, and more social support with higher wellbeing $(\beta=.01, \mathrm{SE}=0.004, p<.001)$. All trait variables were significant, with resilience $(\beta=.08$, $\mathrm{SE}=0.01, p<.001)$, and adaptive perfectionism $(\beta=.004$, $\mathrm{SE}=0.002, p=.03)$, linked to increased wellbeing and workaholism $(\beta=-.01, \mathrm{SE}=0.002, p<.001)$, and maladaptive perfectionism $(\beta=-.01, \mathrm{SE}=0.001, p<.001)$ linked to decreased wellbeing. Studying arts was linked to significantly higher wellbeing $(\beta=.06, \mathrm{SE}=0.02, p=.004)$, as well as a positive self-evaluation of academic progress and preparation $(\beta=.05, \mathrm{SE}=0.008, p<.001)$. There was no multicollinearity in the model (GVIFs $<2)$.

\section{Predictors of suicidal behaviours}

Individuals of bisexual $(\beta=.34, \mathrm{SE}=0.07, p<.001)$ and 'other' sexual orientation $(\beta=.36, \mathrm{SE}=0.13, p=.01)$ had significantly elevated risk of suicide. All trait variables were significant, with workaholism $(\beta=.02, \mathrm{SE}=0.01, p=.004)$ and maladaptive perfectionism $(\beta=.01, \mathrm{SE}=0.004, p=.02)$ having a positive relationship with suicide behaviours and resilience $(\beta=-.13, \mathrm{SE}=0.03, p<.001)$ having a negative relationship with them. More social support significantly reduced the risk of suicide $(\beta=-.03, \mathrm{SE}=0.01, p=.01)$. Departmental climate $(\beta=-.05, \mathrm{SE}=0.02, p=.02)$ and being in the $5^{\text {th }}$ year of study or above $(\beta=.19, \mathrm{SE}=0.09, p=.04)$ had a negative and positive relationship with depression symptoms, respectively. The current model had no multicollinearity issues $(\mathrm{GVIFs}<2)$.

\section{Discussion}

Rates of anxiety, depression, insomnia and suicide behaviours reported by the PGRs in the current study are higher than in the general population (McManus et al., 2016; Mental Health Foundation, 2016; Ohayon,
Table 4 Outcome Variables Descriptive Statistics and Bivariate Correlations

\begin{tabular}{lllllll}
\hline & M & SD & Anxiety & Depression & Sleep & Wellbeing \\
\hline Anxiety & 8.8 & 5.8 & & & & \\
Depression & 9.1 & 6.6 & $0.81^{* * *}$ & & & \\
Sleep & 17.1 & 7.7 & $-0.57^{* * *}$ & $-0.65^{* * *}$ & & \\
Wellbeing & 22.1 & 5.0 & $-0.68^{* * *}$ & $-0.72^{* * *}$ & $0.49^{* * *}$ & \\
Suicidal behaviours & 6.1 & 3.4 & $0.45^{* * *}$ & $0.51^{* * *}$ & $-0.37 * * *$ & $-0.43^{* * *}$ \\
\hline
\end{tabular}

$* * * p<.001$ 
Table 5 Regression Analysis of Predictors of Anxiety, Depression, Sleep, Wellbeing, and Suicidal Behaviours

\begin{tabular}{|c|c|c|c|c|c|}
\hline & Anxiety & Depression & Sleep & Wellbeing & $\begin{array}{l}\text { Suicidal behav- } \\
\text { iours }\end{array}$ \\
\hline \multicolumn{6}{|l|}{ Demographic variables } \\
\hline Age & $-.01 * *$ & $-.01 * *$ & -.004 & .001 & -.001 \\
\hline \multicolumn{6}{|l|}{ Gender identity } \\
\hline \multicolumn{6}{|l|}{ Male (ref) } \\
\hline Female & .12 & $.14 *$ & -.04 & -.02 & .02 \\
\hline Other & .11 & .18 & -.35 & $-.16^{*}$ & .05 \\
\hline \multicolumn{6}{|l|}{ Sexual orientation } \\
\hline \multicolumn{6}{|l|}{ Heterosexual (ref) } \\
\hline Homosexual & -.02 & -.01 & .09 & $-.09 * *$ & .03 \\
\hline Bisexual & .07 & .14 & $-.17 *$ & .01 & $.34 * * *$ \\
\hline Other & -.23 & .02 & -.03 & .04 & $.36^{* *}$ \\
\hline \multicolumn{6}{|l|}{ Trait variables } \\
\hline Resilience & $-.24 * * *$ & $-.23 * * *$ & $.11 * * *$ & $.08 * * *$ & $-.13 * * *$ \\
\hline Workaholism & $.04 * * *$ & $.04 * * *$ & $-.02 * *$ & $-.01 * * *$ & $.02 * *$ \\
\hline Adaptive perfectionism & -.01 & -.01 & -.004 & $.004 *$ & .003 \\
\hline Maladaptive perfectionism & $.02 * * *$ & $.02 * * *$ & -.003 & $-.01 * * *$ & $.01 *$ \\
\hline \multicolumn{6}{|l|}{ Academic variables } \\
\hline Progress & $-.08 * * *$ & $-.16^{* * *}$ & $.08 * * *$ & $.05 * * *$ & -.01 \\
\hline Year-2 & -.04 & -.08 & .06 & .005 & -.03 \\
\hline Year-3 & .05 & -.08 & .02 & -.002 & -.03 \\
\hline Year-4 & .02 & -.04 & .01 & .01 & -.03 \\
\hline Year $-5+$ & -.02 & -.10 & .08 & .03 & $.19^{*}$ \\
\hline \multicolumn{6}{|l|}{ Interpersonal variables } \\
\hline Supervisory relationship & $-.06 * *$ & -.03 & .01 & -.005 & .02 \\
\hline Social support & -.003 & -.01 & .01 & $.01 * * *$ & $-.03 * *$ \\
\hline \multicolumn{6}{|c|}{ Cultural/Institutional variables } \\
\hline Department & -.03 & -.03 & .02 & .01 & $-.05^{*}$ \\
\hline \multicolumn{6}{|l|}{ Field of study } \\
\hline Science \& engineering & -.09 & .06 & .03 & -.02 & .07 \\
\hline MVLS & $-.15^{*}$ & -.02 & -.004 & .02 & -.06 \\
\hline Arts & -.09 & -.08 & .004 & $.06 * *$ & .04 \\
\hline Other & .005 & .11 & -.15 & .02 & .08 \\
\hline \multicolumn{6}{|l|}{ Policy } \\
\hline Funding (self-funded) & .07 & .14 & -.09 & .001 & -.01 \\
\hline Funding (partially funded) & .12 & .08 & .10 & .02 & .07 \\
\hline Multiple Pseudo $\mathbf{R}^{2>}$ & .47 & .48 & .24 & .60 & .34 \\
\hline Adjusted Pseudo $\mathbf{R}^{2>}$ & .44 & .45 & .20 & .57 & .30 \\
\hline
\end{tabular}

$* \mathrm{p}<.05 ; * * \mathrm{p}<.01 * * * \mathrm{p}<.001$
2002). Nevertheless, prevalence of mental ill-health in the current sample of PGRs is comparable to that reported by postgraduates in other countries (e.g. Evans et al., 2018; UC Berkeley Graduate Assembley, 2014), and undergraduates in the UK (Akram et al., 2020; McIntyre et al., 2018), and elsewhere (cf. Alvi et al., 2010; Ibrahim \& Abdelreheem, 2015; Moutinho et al., 2017; Wong et al., 2006). PGR wellbeing, in turn, was lower than in the general population and comparable to that of individuals with self-reported limiting longstanding illnesses (see Ng Fat et al., 2017). Different individual, interpersonal, and institutional factors played a role in the study outcomes, indicating that PGR mental health and wellbeing may best be understood as an interplay between multiple individual and environmental factors. 
Gender and sexual identity were associated with most mental health outcomes. Female gender was a risk factor for depression, while non-binary gender was linked to poorer levels of wellbeing. Non-heterosexual PGRs reported poorer sleep, lower wellbeing and an increased risk of suicide in comparison toheterosexual PGRs. Although these findings reflect the trends in the general population (cf. Mental Health Foundation, 2016), they should also be considered in the context of the research environment. Across national contexts, female (Howe-Walsh \& Turnbull, 2016; Seierstad \& Healy, 2012; Winslow \& Davis, 2016), and sexuality and gender diverse (SGD) ${ }^{4}$ staff and students report experiences of inequality, discrimination, marginalisation and silencing (Ferfolja et al., 2020; Jayakumar, 2009), as well as intimidation, hostility, and harassment (Ellis, 2009; Howe-Walsh \& Turnbull, 2016; Jayakumar, 2009). Both vicarious and experienced discrimination can cause significant stress (Ellis, 2009; Ferfolja et al., 2020) and increase the risk of poorer physical and mental health (Ferfolja et al., 2020; Woodford et al., 2012), which, in combination with other stressors related to postgraduate research, may contribute to the vulnerability of female and SGD researchers.

Resilience, workaholism and perfectionism were linked to a higher number of mental health outcomes than other types of variables. This lends support to the work of Lucas and Diener (2009), who maintain that traits are associated with subjective wellbeing more strongly than life circumstances. Fortunately, traits remain modifiable even in adulthood (Roberts \& DelVecchio, 2000), and there is evidence that resilience, workaholism and perfectionism can be modified through psychoeducational interventions that target the underlying cognitive and behavioural patterns (Caruana et al., 2011; Lloyd et al., 2015). In addition, environmental or contextual factors play a role in the way these traits impact mental wellbeing. While stressful situations exacerbate the negative emotional effects of perfectionism, increased social support and social connectedness seem to ameliorate them (Rice et al., 2006; Zhou et al., 2013). Rice and colleagues (Rice et al., 2006) found that social connectedness decreased the negative effect of maladaptive perfectionism on hopelessness, highlighting the role of social connections in the prevention of suicidal ideation and suicide. These findings strengthen the case for interventions aimed at developing social networks and increasing social support in the research environment.

Academic progress, supervisor's support and departmental climate seem to be highly interconnected (Gardner, 2010;

\footnotetext{
${ }^{4}$ We use the collective term sexuality and gender diverse/diversity (SGD) as it is more inclusive and potentially less stigmatising than the frequently employed terms/acronyms, including lesbian, gay, bisexual, transgender (LGBT; British Psychological Society, 2019).
}

Ismail et al., 2015; Lovitts, 2001). In the current sample, academic progress interacted with all outcomes but suicidal behaviours, which were more common in PGRs with negative departmental experiences, while those who reported poor supervisory relationship had increased anxiety levels. Our findings are in line with Levecque et al. (2017), who showed that inspirational and laissez-faire supervision were associated with low and high levels of PGR psychological distress, respectively. Although qualitative studies provide useful information on personal experiences of the emotional processes involved in supervision (Cotterall, 2013; Gearity \& Mertz, 2012; McAlpine \& McKinnon, 2013; McAlpine et al., 2012), our study is one of the few that provides knowledge about the links between this relationship and specific mental health outcomes.

Supervisors also play a major role in the socialisation and integration of PGRs, which, in turn, are key to successful completion. Many PGRs who chose to abandon their programmes often described themselves as poorly integrated and their departments as non-cohesive and difficult to navigate (Lovitts, 2001). Poor integration may also originate from excessive task orientation, i.e. workaholism, be it on the part of PGRs or academic staff, or both (Janta et al., 2014; Lovitts, 2001). On the other hand, departments with high completion rates have been described by PGRs as having clear expectations, fostering supportive mentoring relationships and providing students with opportunities for social and academic integration and participation in departmental governance (Lovitts, 2001).

The fact that being in the $5^{\text {th }}$ year of postgraduate research, or above, increased the risk of suicidal behaviours lends support to Barry et al. (2018), who showed that being behind schedule was negatively related to the mental wellbeing of doctoral candidates. This may be underpinned by the difficulties that have contributed to the late completion, as well as exacerbated by the fact that these PGRs are likely to be cut off from the campus and the social and psychological support available therein. However, the present sample also includes part-time researchers, who may not necessarily be behind schedule, but are likely to be missing out on the oncampus experience (cf. Metcalfe et al., 2018). Contrary to previous findings (e.g. UC Berkeley Graduate Assembley, 2014), studying arts had a positive relationship with wellbeing, while medical, veterinary and life sciences were linked to lower anxiety rates, supporting similar findings from undergraduate samples (Bayram \& Bilgel, 2008; Bunevicius et al., 2008). Nevertheless, this finding is limited by the fact that field of study was derived from the question about the college/school of registration and answers are likely to vary with the idiosyncrasies in institutional administrative structures across the UK institutions. The extent of funding available did not have a significant effect on PGR mental wellbeing. 
PGRs in this study reported lower levels of wellbeing than highly educated individuals of a comparable age in the general population (Ng Fat et al., 2017). The fact that eudaimonic wellbeing was higher than hedonic implies that PGR welfare may be grounded in psychosocial functioning and the sense of meaningfulness, rather than happiness. While happiness grows with the satisfaction of needs and desires, meaningfulness increases when one focuses on identity and the expression of self. Nevertheless, worry, stress, and anxiety are linked with higher meaningfulness but lower happiness (Baumeister et al., 2013). This indicates that while the engagement with postgraduate research might provide a deeply meaningful self-realisation opportunity, its demands may cause stress and stand in the way of work-life balance and needs satisfaction, thus potentially diminishing positive emotions.

The current study has several limitations that future research should address. First, the cross-sectional design it employs is a 'snapshot in time' (Grimes \& Schulz, 2002, p58) and cannot explain the causal mechanisms behind our findings, i.e. whether, for example, anxiety stems from hindered progression, or it prevents individuals from progressing satisfactorily. Second, the study used brief self-report measures of mental health outcomes, which, although validated in various populations, do not equal clinical diagnoses. To lessen participant burden, we used shorter, adapted versions of standard questionnaires to assess social support and workaholism, which may not capture the constructs in question as well as the longer, validated versions. For want of validated scales to assess departmental climate and supervisory relationship, we created novel, unvalidated scales for the purposes of the current study that may limit the validity of the said outcomes. However, we provide an account of how the scales were composed and used in the supplemental materials, in order to maximise transparency. Third, a relatively small sample size and over-representation of female and Scottish students may limit the generalisability of findings. As prevalence of mental health problems and suicidal ideation is higher in females than in males (McManus et al., 2016), this may have contributed to the high prevalence rates in this study. In order to limit response bias, the survey was advertised as looking into PGR wellbeing, which is a more neutral term than 'mental health'. Nevertheless, it is still possible that individuals who were experiencing poor wellbeing at the time were more motivated to take part, contributing to the high prevalence of self-reported mental health symptoms. Future research should address these limitations by using large random samples and employing a longitudinal design. Further exploration of ways in which different individual, interpersonal and environmental factors interact to shape PGR wellbeing is also warranted. For example, studies could help establish whether perceived institutional equality, diversity and inclusion mediate the relationship between gender/sexual orientation and wellbeing or how departmental climate and supervisory relationship interact with workaholism and perfectionism.

Our findings have several implications for policy and practice. They indicate that potential interventions to improve PGR wellbeing should target multiple factors. Namely, universities need to be proactive in ending bullying and discrimination and increasing diversity, with the commitment to these goals clearly reflected in policy, outreach, recruitment, curricula, social groups, merchandise, etc. Furthermore, departments should aim to implement policies and procedures to create communities that facilitate PGR integration and optimal academic, social, and emotional functioning of all members. These may include, but not be limited to, designing comprehensive departmental orientation programmes, supplying clear and consistent guidance and information with regards to expectations, rules and regulations, facilitating social interactions between students and faculty, modelling a healthy work-life balance, encouraging students to participate in departmental governance, and seminar series that feature internal research projects and similar (Golde \& Dore, 2001; Lovitts, 2001; Nelson \& Lovitts, 2001) Finally, our findings on the effect of traits may help inform the counselling practice for PGRs. Psychological services could facilitate group training in cognitive and behavioural skills to increase resilience and tackle workaholism and perfectionism. Development of these skills can also be facilitated through a variety of programmes and activities that, in turn, have the added benefit of increasing social support and connectedness (Holdsworth et al., 2018).

\section{Conclusion}

The current study contributes to the growing body of literature on PGR mental health by showing that the rates of mental ill-health in PGRs in the current sample are high and shaped by a combination of factors, including gender and sexual orientation, individual differences in resilience, workaholism and perfectionism, as well as the perceived academic progress and preparation, social support and 
departmental climate. Universities may aim to enhance PGR welfare by committing to the values of equality, inclusivity and diversity, and promoting PGR integration, social support and a healthy work-life balance.

Supplementary Information The online version contains supplementary material available at https://doi.org/10.1007/s12144-021-02309-y.

Funding The current study is the first of a larger mixed methods research portfolio exploring PGR wellbeing funded by the University of Glasgow Research and Innovation Services to the senior author (MG). JM is supported by an MRC PhD studentship (MC_ST_00022). SAS and MMcC are supported by the Chief Scientist Office of the Scottish Government Health and Social Care Directorates at the MRC/ CSO Social \& Public Health Sciences Unit, University of Glasgow (MC_UU_00022/1, SPHSU16; MC_UU_00022/3, SPHSU18).

Data availability We have deposited the anonymised data set with UK Data Service: https://doi.org/10.5255/UKDA-SN-855193.

\section{Declarations}

Conflict of interest No potential conflict of interest was reported by the authors.

Open Access This article is licensed under a Creative Commons Attribution 4.0 International License, which permits use, sharing, adaptation, distribution and reproduction in any medium or format, as long as you give appropriate credit to the original author(s) and the source, provide a link to the Creative Commons licence, and indicate if changes were made. The images or other third party material in this article are included in the article's Creative Commons licence, unless indicated otherwise in a credit line to the material. If material is not included in the article's Creative Commons licence and your intended use is not permitted by statutory regulation or exceeds the permitted use, you will need to obtain permission directly from the copyright holder. To view a copy of this licence, visit http://creativecommons.org/licenses/by/4.0/.

\section{References}

Akram, U., Ypsilanti, A., Gardani, M., Irvine, K., Allen, S., Akram, A., Drabble, J., Bickle, E., Kaye, L., Lipinski, D., Matuszyk, E., Sarlak, H., Steedman, E., \& Lazuras, L. (2020). Prevalence and psychiatric correlates of suicidal ideation in UK university students. Journal of Affective Disorders, 272, 191-197. https:// doi.org/10.1016/j.jad.2020.03.185

Ali, P., Watson, P., \& Dhingra, K. (2016). Postgraduate Research Students' and their Supervisors' Attitudes towards Supervision. International Journal of Doctoral Studies, 11, 227-241.

Alvi, T., Assad, F., Ramzan, M., \& Khan, F. A. (2010). Depression, Anxiety and Their Associated Factors Among Medical Students. 20,5

Aswini, S., \& Amrita, D. (2017). Flourishing among postgraduate students: The role of resilience, meaningfulness and grit. Indian J. Commun. Psychol, 13(1), 24-37.

Barbosa, A. M., Brown J.A., Jimenez-Valverde A., \& Real R. (2021). Model Evaluation and Analysis (2.0) [Computer software].

Barry, K. M., Woods, M., Warnecke, E., Stirling, C., \& Martin, A. (2018). Psychological health of doctoral candidates, study-related challenges and perceived performance. Higher
Education Research \& Development, 37(3), 468-483. https:// doi.org/10.1080/07294360.2018.1425979

Baumeister, R. F., Vohs, K. D., Aaker, J. L., \& Garbinsky, E. N. (2013). Some key differences between a happy life and a meaningful life. The Journal of Positive Psychology, 8(6), 505-516. https://doi.org/10.1080/17439760.2013.830764

Bayram, N., \& Bilgel, N. (2008). The prevalence and socio-demographic correlations of depression, anxiety and stress among a group of university students. Social Psychiatry and Psychiatric Epidemiology, 43(8), 667-672. https://doi.org/10.1007/ s00127-008-0345-x

Beasly, M., Thompson, T., \& Davidson, J. (2003). Resilience in response to life stress: The effects of coping style and cognitive hardiness. Personality and Individual Differences, 34, $77-95$.

Bronfenbrenner, U. (1977). Toward an experimental ecology of human development. American Psychologist, 32(7), 513-531. https://doi.org/10.1037/0003-066X.32.7.513

Bunevicius, A., Katkute, A., \& Bunevicius, R. (2008). Symptoms of Anxiety and Depression in Medical Students and in Humanities Students: Relationship With Big-Five Personality Dimensions and Vulnerability To Stress. International Journal of Social Psychiatry, 54(6), 494-501. https://doi.org/10.1177/00207 64008090843

Burnham, K. P., Anderson, D. R., \& Huyvaert, K. P. (2011). AIC model selection and multimodel inference in behavioral ecology: Some background, observations, and comparisons. Behavioral Ecology and Sociobiology, 65(1), 23-35. https://doi.org/10.1007/ s00265-010-1029-6

Caesens, G., Stinglhamber, F., \& Luypaert, G. (2014). The impact of work engagement and workaholism on well-being: The role of work-related social support. Career Development International, 19(7), 813-835. https://doi.org/10.1108/CDI-09-2013-0114

Caruana, V., Clegg, S., Ploner, J., Stevenson, J., \& Wood, R. (2011). Promoting students' 'resilient thinking' in diverse higher education learning environments. Birmingham: HE Academy Subject Centre for Sociology, Anthropology and Politics. Retrieved June 5, 2019, from: https://www.heacademy.ac.uk/system/files/C-SAP_ Literature_Review020811.pdf

Cotterall, S. (2013). More than just a brain: Emotions and the doctoral experience. Higher Education Research \& Development, 32(2), 174-187. https://doi.org/10.1080/07294360.2012.680017

Cowling, M. (2017). Happiness in UK postgraduate research. Higher Education Academy. Retrieved March 11, 2019, from: https:// www.advance-he.ac.uk/knowledge-hub/happiness-uk-post-gradu ate-research-uk-heis?PageSpeed=noscript

Dunn, P. (2021). Evaluation of Tweedie Exponential Family Models (2.3.3) [Computer software].

Dunn, P. K., \& Smyth, G. K. (2018). Generalized Linear Models With Examples in R. Springer, New York. https://doi.org/10.1007/ 978-1-4419-0118-7

Ellis, S. J. (2009). Diversity and inclusivity at university: A survey of the experiences of lesbian, gay, bisexual and trans (LGBT) students in the UK. Higher Education, 57(6), 723-739. https:// doi.org/10.1007/s10734-008-9172-y

Espie, C. A., Kyle, S. D., Hames, P., Gardani, M., Fleming, L., \& Cape, J. (2014). The Sleep Condition Indicator: A clinical screening tool to evaluate insomnia disorder. British Medical Journal Open, 4(3), e004183. https://doi.org/10.1136/bmjop en-2013-004183

Evans, T. M., Bira, L., Gastelum, J. B., Weiss, L. T., \& Vanderford, N. L. (2018). Evidence for a mental health crisis in graduate education. Nature Biotechnology, 36(3), 282-284. https://doi.org/10. 1038/nbt.4089 
Fahrmeir, L., Kneib, T., Lang, S., \& Marx, B. (2013). Regression, Models, Methods and Applications. Springer, Berlin Heidelberg. https://doi.org/10.1007/978-3-642-34333-9

Ferfolja, T., Asquith, N., Hanckel, B., \& Brady, B. (2020). In/visibility on campus? Gender and sexuality diversity in tertiary institutions. Higher Education. https://doi.org/10.1007/s10734-020-00526-1

Flowers, C. P., \& Robinson, B. (2002). A Structural and Discriminant Analysis of the Work Addiction Risk Test. Educational and Psychological Measurement, 62(3), 517-526. https://doi.org/10.1177/ 00164402062003008

Gardner, S. K. (2010). Contrasting the Socialization Experiences of Doctoral Students in High- and Low-Completing Departments: A Qualitative Analysis of Disciplinary Contexts at One Institution. The Journal of Higher Education, 81(1), 61-81. https://doi.org/ 10.1080/00221546.2010.11778970

Gearity, B. T., \& Mertz, N. (2012). From "Bitch" to "Mentor": A Doctoral Student's Story of Self-Change and Mentoring. 27

Golde, C. M., \& Dore, T. M. (2001). At cross purposes: What the experiences of today's doctoral students reveal about doctoral education. Retrieved May 20, 2020, from https://eric.ed.gov/?id= ED450628

Goldstein, A. N., Greer, S. M., Saletin, J. M., Harvey, A. G., Nitschke, J. B., \& Walker, M. P. (2013). Tired and apprehensive: Anxiety amplifies the impact of sleep loss on aversive brain anticipation. The Journal of Neuroscience: The Official Journal of the Society for Neuroscience, 33(26), 10607-10615. https://doi.org/10.1523/ JNEUROSCI.5578-12.2013

Grimes, D. A., \& Schulz, K. F. (2002). An overview of clinical research: The lay of the land. The Lancet, 359(9300), 57-61. https://doi.org/10.1016/S0140-6736(02)07283-5

Guisan, A., \& Zimmermann, N. E. (2000). Predictive habitat distribution models in ecology. Ecological Modelling, 135(2-3), 147186. https://doi.org/10.1016/S0304-3800(00)00354-9

Hazell, C. M., Chapman, L., Valeix, S. F., Roberts, P., Niven, J. E., \& Berry, C. (2020). Understanding the mental health of doctoral researchers: A mixed methods systematic review with meta-analysis and meta-synthesis. Systematic Reviews, 9(1), 197. https:// doi.org/10.1186/s13643-020-01443-1

Higher Education Statistics Agency. (2020). UK domiciled student enrolments by disability and sex. Hesa.Ac.Uk. Retrieved September 3, 2020, from: https://www.hesa.ac.uk/data-and-analysis/ students/table-15

Holdsworth, S., Turner, M., \& Scott-Young, C. M. (2018). ... Not drowning, waving. Resilience and university: A student perspective. Studies in Higher Education, 43(11), 1837-1853. https://doi. org/10.1080/03075079.2017.1284193

Howe-Walsh, L., \& Turnbull, S. (2016). Barriers to women leaders in academia: Tales from science and technology. Studies in Higher Education, 41(3), 415-428. https://doi.org/10.1080/03075079. 2014.929102

Ibrahim, M. B., \& Abdelreheem, M. H. (2015). Prevalence of anxiety and depression among medical and pharmaceutical students in Alexandria University. Alexandria Journal of Medicine, 51(2), 167-173. https://doi.org/10.1016/j.ajme.2014.06.002

Ismail, A., Kho Khian Jui, M., Md Sham, F. F., \& Abdullah, N. (2015). Effect of Mentoring Program on Mentees' Academic Performance from an Islamic Perspective. Islamiyyat, 37(1), 29-38. https://doi.org/10.17576/islamiyyat-2015-3701-03

Janta, H., Lugosi, P., \& Brown, L. (2014). Coping with loneliness: A netnographic study of doctoral students. Journal of Further and Higher Education, 38(4), 553-571. https://doi.org/10.1080/ 0309877X.2012.726972

Jayakumar, U. M. (2009). The Invisible Rainbow in Diversity: Factors Influencing Sexual Prejudice Among College Students. Journal of Homosexuality, 56(6), 675-700. https://doi.org/10. $1080 / 00918360903054095$
Jiang, X.-L., Zheng, X.-Y., Yang, J., Ye, C.-P., Chen, Y.-Y., Zhang, Z.-G., \& Xiao, Z.-J. (2015). A systematic review of studies on the prevalence of Insomnia in university students. Public Health, 129(12), 1579-1584. https://doi.org/10.1016/j.puhe. 2015.07.030

Kalmbach, D. A., Cuamatzi-Castelan, A. S., Tonnu, C. V., Tran, K. M., Anderson, J. R., Roth, T., \& Drake, C. L. (2018). Hyperarousal and sleep reactivity in insomnia: Current insights. Nature and Science of Sleep, 10, 193-201. https://doi.org/10.2147/NSS.S138823

Kroenke, K., \& Spitzer, R. L. (2002). The PHQ-9: A New Depression Diagnostic and Severity Measure. Psychiatric Annals, 32(9), 509-515. https://doi.org/10.3928/0048-5713-20020901-06

Kroenke, K., Spitzer, R. L., \& Williams, J. B. W. (2001). The PHQ-9. Journal of General Internal Medicine, 16(9), 606-613. https:// doi.org/10.1046/j.1525-1497.2001.016009606.x

Levecque, K., Anseel, F., De Beuckelaer, A., Van der Heyden, J., \& Gisle, L. (2017). Work organization and mental health problems in PhD students. Research Policy, 46(4), 868-879. https://doi.org/ 10.1016/j.respol.2017.02.008

Lipson, S. K., Zhou, S., Wagner, B., Beck, K., \& Eisenberg, D. (2016). Major Differences: Variations in Undergraduate and Graduate Student Mental Health and Treatment Utilization Across Academic Disciplines. Journal of College Student Psychotherapy, 30(1), 23-41. https://doi.org/10.1080/87568225.2016.1105657

Lloyd, S., Schmidt, U., Khondoker, M., \& Tchanturia, K. (2015). Can Psychological Interventions Reduce Perfectionism? A Systematic Review and Meta-analysis. Behavioural and Cognitive Psychotherapy, 43(6), 705-731. https://doi.org/10.1017/S135246581 4000162

Lovitts, B. E. (2001). Leaving the ivory tower: The causes and consequences of departurefrom doctoral study. Rowman and Littlefield.

Lucas, R. E., \& Diener, E. (2009). Personality and subjective wellbeing. In The science of well-being: The collected works of Ed Diener (pp. 75-102). Springer Science + Business Media

McAlpine, L., \& McKinnon, M. (2013). Supervision - the most variable of variables: Student perspectives. Studies in Continuing Education, 35(3), 265-280. https://doi.org/10.1080/0158037X. 2012.746227

McAlpine, L., Paulson, J., Gonsalves, A., \& Jazvac-Martek, M. (2012). 'Untold' doctoral stories: Can we move beyond cultural narratives of neglect? Higher Education Research \& Development, 31(4), 511-523. https://doi.org/10.1080/07294360.2011.559199

McIntyre, J. C., Worsley, J., Corcoran, R., Woods, P. H., \& Bentall, R. P. (2018). Academic and non-academic predictors of student psychological distress: The role of social identity and loneliness. Journal of Mental Health, 27(3), 230-239. https://doi.org/10. 1080/09638237.2018.1437608

McLeroy, K. R., Bibeau, D., Steckler, A., \& Glanz, K. (1988). An Ecological Perspective on Health Promotion Programs. Health Education Quarterly, 15(4), 351-377. https://doi.org/10.1177/ 109019818801500401

McManus, S., Bebbington, P., Jenkins, R., \& Brugha, T. (2016). Mental health and wellbeing in England: Adult Psychiatric Morbidity Survey 2014. NHS Digital.

Mental Health Foundation. (2016). Fundamental facts about mental health 2016. Mental Health Foundation. Retrieved June 16, 2019, from: https://www.mentalhealth.org.uk/sites/default/files/funda mental-facts-about-mental-health-2016.pdf

Merz, E. L., Roesch, S. C., Malcarne, V. L., Penedo, F. J., Llabre, M. M., Weitzman, O. B., Navas-Nacher, E. L., Perreira, K. M., Gonzalez, F., II., Ponguta, L. A., Johnson, T. P., \& Gallo, L. C. (2014). Validation of Interpersonal Support Evaluation List-12 (ISEL-12) scores among English- and Spanish-speaking Hispanics/Latinos from the HCHS/SOL Sociocultural Ancillary Study. Psychological Assessment, 26(2), 384-394. https://doi.org/10.1037/a0035248 
Metcalfe, J., Wilson, S., \& Levecque, K. (2018). Exploring wellbeing and mental health and associated support services for postgraduate researchers. Vitae. Retrieved May 12, 2019, from: https://re. ukri.org/documents/2018/mental-health-report/

Milicev, J., Biello, S., \& Gardani, M. (2018). Postgraduate Research Students' Mental Health and the Role of the Supervisor-A Mixed Methods Study. OSF. https://osf.io/zd3ws/

Moate, R. M., Gnilka, P. B., West, E. M., \& Rice, K. G. (2019). Doctoral Student Perfectionism and Emotional Well-Being. Measurement and Evaluation in Counseling and Development, 52(3), 145-155. https://doi.org/10.1080/07481756.2018.1547619

Montgomery, D. C., Peck, E. A., \& Vining, G. G. (2012). Introduction to Linear Regression Analysis. Wiley.

Mortier, P., Cuijpers, P., Kiekens, G., Auerbach, R. P., Demyttenaere, K., Green, J. G., Kessler, R. C., Nock, M. K., \& Bruffaerts, R. (2018). The prevalence of suicidal thoughts and behaviours among college students: A meta-analysis. Psychological Medicine, 48(4), 554-565. https://doi.org/10.1017/S0033291717002215

Moutinho, I. L. D., Maddalena, N. de C. P., Roland, R. K., Lucchetti, A. L. G., Tibiriçá, S. H. C., Ezequiel, O. da S., Lucchetti, G., \& Universidade Federal de Juiz de Fora, Brazil. (2017). Depression, stress and anxiety in medical students: A cross-sectional comparison between students from different semesters. Revista Da Associação Médica Brasileira, 63(1), 21-28. https://doi.org/ 10.1590/1806-9282.63.01.21

Nelson, C., \& Lovitts, B. E. (2001, June 29). 10 Ways to Keep Graduate Students From Quitting. The Chronicle of Higher Education. https://www.chronicle.com/article/10-Ways-to-Keep-Graduate/ 6173

Nelson, N. G., Dell'Oliver, C., Koch, C., \& Buckler, R. (2001). Stress, coping, and success among graduate students in clinical psychology. Psychological Reports, 88(3), 759-767. https://doi.org/10. 2466/pr0.2001.88.3.759.

Ng Fat, L., Scholes, S., Boniface, S., Mindell, J., \& Stewart-Brown, S. (2017). Evaluating and establishing national norms for mental wellbeing using the short Warwick-Edinburgh Mental Well-being Scale (SWEMWBS): Findings from the Health Survey for England. Quality of Life Research, 26(5), 1129-1144. https://doi.org/ 10.1007/s11136-016-1454-8

Ohayon, M. M. (2002). Epidemiology of insomnia: What we know and what we still need to learn. Sleep Medicine Reviews, 6(2), 97-111. https://doi.org/10.1053/smrv.2002.0186

Osman, A., Bagge, C. L., Gutierrez, P. M., Konick, L. C., Kopper, B. A., \& Barrios, F. X. (2001). The Suicidal Behaviors Questionnaire-Revised (SBQ-R): Validation with Clinical and Nonclinical Samples. Assessment, 8(4), 443-454. https://doi.org/10.1177/ 107319110100800409

R Core Team. (2019). R: The R Project for Statistical Computing. https://www.r-project.org/

Rice, K. G., Leever, B. A., Christopher, J., \& Porter, J. D. (2006). Perfectionism, stress, and social (dis)connection: A short-term study of hopelessness, depression, and academic adjustment among honors students. Journal of Counseling Psychology, 53(4), 524-534. https://doi.org/10.1037/0022-0167.53.4.524

Rice, K. G., Richardson, C. M. E., \& Tueller, S. (2014). The Short Form of the Revised Almost Perfect Scale. Journal of Personality Assessment, 96(3), 368-379. https://doi.org/10.1080/00223891. 2013.838172

Ríos-Risquez, M. I., García-Izquierdo, M., Sabuco-Tebar, E. de los A., Carrillo-Garcia, C., \& Martinez-Roche, M. E. (2016). An exploratory study of the relationship between resilience, academic burnout and psychological health in nursing students. Contemporary Nurse, 52(4), 430-439. https://doi.org/10.1080/10376178.2016. 1213648

Roberts, B. W., \& DelVecchio, W. F. (2000). The rank-order consistency of personality traits from childhood to old age: A quantitative review of longitudinal studies. Psychological Bulletin, 126(1), 3-25. https://doi.org/10.1037/0033-2909.126.1.3

Robinson, B. E. (1999). The Work Addiction Risk Test: Development of a Tentative Measure of Workaholism. Perceptual and Motor Skills, 88(1), 199-210. https://doi.org/10.2466/pms.1999.88.1.199

Rose, G. (2005). Group differences in graduate students' conceptions of the ideal mentor. Research in Higher Education, 46(1), 53-80.

Russell, K., Allan, S., Beattie, L., Bohan, J., MacMahon, K., \& Rasmussen, S. (2019). Sleep problem, suicide and self-harm in university students: A systematic review. Sleep Medicine Reviews, 44, 58-69. https://doi.org/10.1016/j.smrv.2018.12.008

Schmidt, M., \& Hansson, E. (2018). Doctoral students' well-being: A literature review. International Journal of Qualitative Studies on Health and Well-Being, 13(1), 1508171. https://doi.org/10.1080/ 17482631.2018 .1508171

Seierstad, C., \& Healy, G. (2012). Women's equality in the Scandinavian academy: A distant dream? Work, Employment and Society, 26(2), 296-313. https://doi.org/10.1177/0950017011432918

Sheaves, B., Porcheret, K., Tsanas, A., Espie, C. A., Foster, R. G., Freeman, D., Harrison, P. J., Wulff, K., \& Goodwin, G. M. (2016). Insomnia, Nightmares, and Chronotype as Markers of Risk for Severe Mental Illness: Results from a Student Population. Sleep, 39(1), 173-181. https://doi.org/10.5665/sleep.5342

Slight, C. (2017). Postgraduate research experience Survey 2017. Higher Education Academy. Retrieved May 9, 2019, from: https:// www.advance-he.ac.uk/knowledge-hub/postgraduate-researchexperience-survey-report-2017

Smith, B. W., Dalen, J., Wiggins, K., Tooley, E., Christopher, P., \& Bernard, J. (2008). The brief resilience scale: Assessing the ability to bounce back. International Journal of Behavioral Medicine, 15(3), 194-200. https://doi.org/10.1080/10705500802222972

Smith, E., \& Brooks, Z. (2015). Graduate student mental health 2015. National Association of Graduate-Professional Students and The Graduate Professional Student Council, University of Arizona. Retrieved June 9, 2019, from: http://nagps.org/wordpress/wpcontent/uploads/2015/06/NAGPS_Institute_mental_health_survey_report_2015.pdf

Spitzer, R. L., Kroenke, K., Williams, J. B. W., \& Löwe, B. (2006) A Brief Measure for Assessing Generalized Anxiety Disorder: The GAD-7. Archives of Internal Medicine, 166(10), 1092-1097. https://doi.org/10.1001/archinte.166.10.1092

Stewart-Brown, S., Tennant, A., Tennant, R., Platt, S., Parkinson, J., \& Weich, S. (2009). Short Warwick Edinburgh Mental Well-Being Scale (SWEMWBS) (appears in: Internal Construct Validity of the Warwick-Edinburgh Mental Well-Being Scale (WEMWBS): A Rasch Analysis Using Data from the Scottish Health Education Population Survey). Copyright: Creative Commons License. Tests \& Measurements, 7(Feb. 19), 15. https://doi.org/10.1186/ 1477-7525-7-15

Sverdlik, A., Hall, N. C., McAlpine, L., \& Hubbard, K. (2018). The PhD Experience: A Review of the Factors Influencing Doctoral Students' Completion, Achievement, and Well-Being. International Journal of Doctoral Studies, 13, 361-388. https://doi.org/ $10.28945 / 4113$

UC Berkeley Graduate Assembly. (2014). Graduate student happiness \& well-being report. Retrieved October 15, 2018, from: http:// ga.berkeley.edu/wp-content/uploads/2015/04/wellbeingreport_ 2014.pdf

University of California Student Mental Health Committee. (2006). Report of the University of California Student Mental Health Committee. University of California

Väisänen, S., Pietarinen, J., Pyhältö, K., Toom, A., \& Soini, T. (2017). Social support as a contributor to student teachers' experienced well-being. Research Papers in Education, 32(1), 41-55. https:// doi.org/10.1080/02671522.2015.1129643 
Winslow, S., \& Davis, S. N. (2016). Gender Inequality Across the Academic Life Course: Gender Inequality Across the Academic Life Course. Sociology Compass, 10(5), 404-416. https://doi.org/ $10.1111 /$ soc4.12372

Wong, J. G. W. S., Cheung, E. P. T., Chan, K. K. C., Ma, K. K. M., \& Wa Tang, S. (2006). Web-Based Survey of Depression, Anxiety and Stress in First-Year Tertiary Education Students in Hong Kong. Australian \& New Zealand Journal of Psychiatry, 40(9), 777-782. https://doi.org/10.1080/j.1440-1614.2006.01883.x

Woodford, M. R., Howell, M. L., Silverschanz, P., \& Yu, L. (2012). "That's So Gay!": Examining the Covariates of Hearing This Expression Among Gay, Lesbian, and Bisexual College Students.
Journal of American College Health, 60(6), 429-434. https://doi. org/10.1080/07448481.2012.673519

Zhou, X., Zhu, H., Zhang, B., \& Cai, T. (2013). Perceived Social Support as Moderator of Perfectionism, Depression, and Anxiety in College Students. Social Behavior and Personality: An International Journal, 41(7), 1141-1152. https://doi.org/10.2224/sbp. 2013.41.7.1141

Publisher's note Springer Nature remains neutral with regard to jurisdictional claims in published maps and institutional affiliations. 